\title{
Angiographic abnormalities associated with alterations in regional myocardial blood flow in coronary artery disease ${ }^{1,2}$
}

\author{
Jackie R. See, Peter F. Cohn, B. Leonard Holman, Barbara H. Roberts, and \\ Douglass F. Adams \\ From the Departments of Medicine and Radiology, Peter Bent Brigham Hospital and Harvard Medical \\ School, Boston, Massachusetts, U.S.A.
}

To evaluate the association between alterations in myocardial blood flow and angiographic findings, myocardial blood flow was compared in 26 patients with asynergy, 15 patients with a similar extent of coronary artery disease but without asynergy, and 10 patients without coronary artery disease or obvious myocardial or valvular disease. Myocardial blood flow was measured at rest with an Anger camera and PDP-11/20 computer after the intracoronary injection of ${ }^{133}$ xenon. In comparison with the normal subjects, whole heart blood flow was significantly reduced in patients with asynergy. In addition, myocardial blood flow in regions of anteroapical asynergy was reduced $\left(85.7 \pm 7.0 \mathrm{ml} / \mathrm{min}\right.$ per $100 \mathrm{~g}^{3}$ in controls to $\left.65.4 \pm 4.5, P<0.05\right)$ and a similar reduction was noted in regions of posterolateral asynergy $(91 \cdot 5 \pm 8 \cdot 8$ in controls to $66 \cdot 8 \pm 5 \cdot 0$, $P<0.05)$. In general, regional myocardial blood flow was reduced distal to left anterior descending or left circumflex stenosis of $>50$ per cent, with a trend toward further reduction distal to $>75$ per cent stenosis. In these same patients, the presence of anteroapical or posterolateral asynergy resulted in a similar trend to even greater reduction of flow. The effect of collaterals was variable: 7 of 8 patients without asynergy but with $>75$ per cent left anterior descending stenosis and collateral circulation to the lower left anterior descending quadrant had minimally reduced flows. However, in the 17 patients with anteroapical asynergy, regional myocardial blood flow was very similar in the 9 patients with collaterals compared with the 8 patients without them. This study suggests that the degree of coronary artery stenosis and presence of asynergy are both important in evaluating alterations in myocardial blood flow in coronary artery disease, while the role of collaterals remains uncertain.

The relation between alterations in regional myocardial blood flow and angiographic abnormalities of the coronary arteries and left ventricle remains unclear (Cannon, Dell, and Dwyer, 1972a; Klocke et al., 1974). In the present study, we have approached this problem by measuring whole heart blood flow and regional myocardial blood flow simultaneously, and by noting (1) to what extent regional flow is reduced in areas of abnormal left ventricular wall motion (asynergy) and (2) what the relation of this flow reduction is to the degree of

\section{Received 1 March 1976.}

${ }^{1}$ This work was supported by a USPHS Grant.

${ }^{2}$ Presented at the 48th Annual Scientific Sessions of the American Heart Association, Anaheim, California, November 1975.

${ }^{3}$ Mean \pm SEM. asynergy, the degree of coronary artery stenosis, and the presence or absence of coronary collateral circulation.

\section{Patients and methods}

\section{Patient selection}

After giving informed consent, 51 patients with a chest pain syndrome were evaluated with biplane left ventriculography and selective coronary angiography, followed by selective injection of ${ }^{133}$ xenon into the left main coronary artery. These patients were not selected in any systematic fashion except that patients with unstable angina or concomitant cardiomyopathies or valvular heart disease were excluded. This series included 10 patients with a chest pain syndrome and normal coronary arterio- 
grams and left ventriculograms. This normal control group of 7 men and 3 women did not have any clinical or angiographic evidence of valvular disease or primary myocardial disease. The mean age of this group was 46 years (range 38 to 57 ).

\section{Catheterization procedure}

Each patient was in the fasting state and was premedicated with $50 \mathrm{mg}$ diphenhydramine and $10 \mathrm{mg}$ diazepam orally or intramuscularly. Right and left heart catheterization with biplane left ventriculography were performed. Selective coronary angiography was then done via the femoral approach, followed by blood flow measurements using ${ }^{133}$ xenon.

All data concerning percentage luminal diameter stenosis and presence or absence of collaterals were determined by the consensus of 3 independent investigators. Axis shortening from end-diastole to end-systole was determined from hand-drawn ventriculographic silhouettes. End-diastole was defined as the largest silhouette, end-systole the smallest. One investigator drew all silhouettes to ensure standardization of technique and to eliminate possible intraobserver differences (Cohn et al., 1974b). Only the first 4 regularly conducted beats after complete opacification of the ventricle were used. The reproducibility of these silhouettes from one early beat to the next in the same ventriculogram has been previously shown in our laboratory (Cohn et al., 1974b). The lower limits of normal values for axis shortening in our laboratory are $\geqslant 10$ per cent shortening in the longitudinal axis in the right anterior oblique projection and $\geqslant 20$ per cent shortening in the major transverse axes in both the right and left anterior oblique projections. Posterolateral asynergy was evaluated in the left anterior oblique projection (Cohn et al., 1974a). Posterolateral hypokinesis was defined as 5 to 20 per cent shortening in the posterolateral transverse radius in this projection and akinesis as $<5$ per cent shortening in this radius. Posterolateral dyskinesis was not observed in this series of patients. Anteroapical hypokinesis was defined as either 2 to 10 per cent shortening in the longitudinal axis in the right anterior oblique projection and/or 5 to 20 per cent shortening in the anterior transverse radius; akinesis was defined as $<2$ per cent shortening in the longitudinal axis and $<5$ per cent shortening in the transverse radius. Again, anteroapical dyskinesis was not present in this series of patients. No attempt was made to evaluate septal asynergy in the left anterior oblique projection because of variable effects on septal motion depending on the level of obstruction in the left anterior descending artery, and because flow in the right coronary artery-which usually supplies the posterior part of the septum-was not studied. Patients with both posterolateral and anteroapical asynergy were assigned to one of the two respective subgroups depending on which was the more severe abnormality.

At least 10 minutes were allowed to elapse between the last injection of contrast medium (meglumine and sodium diatrizoate) for diagnostic coronary angiography before the selective injection of xenon was attempted. To allow haemodynamic values to return to baseline levels, at least 30 minutes were allowed to elapse between the last sublingual administration of nitroglycerin and the intracoronary injection of xenon.

\section{Measurement of regional myocardial blood flow}

The patient was placed in the left anterior oblique position under the fluoroscopy unit where the centre and borders of the heart were marked on the chest. The table was then placed under the Anger scintillation camera (Nuclear Chicago Pho/Gamma HP). A radioactive source was moved over the borders of the heart, and the relation between the camera detector and the table was recorded. The patient was repositioned under the fluoroscopy unit, a catheter was placed in the left main coronary artery and its position confirmed by injection of $0.25 \mathrm{ml}$ contrast material. The table was repositioned under the Anger camera in the left anterior oblique position, and 20 to $25 \mathrm{mCi}$ of ${ }^{133} \mathrm{Xe}$ in $2 \mathrm{ml}$ saline were injected followed by a $3 \mathrm{ml}$ saline flush. The catheter was then removed from the coronary artery.

Washout curves were constructed using 2-second time frames from the peak to 40 seconds afterwards, and regional washout curves were obtained by placing electronic cursors over the proximal and distal portions of the left anterior descending and left circumflex coronary arteries (4 quadrants) (Fig. 1). The position of these vessels was determined from the initial frames of the gamma camera image during the arterial phase of the study and myocardial blood flow was calculated from the initial slope of the xenon clearance curve (Ross et al., 1964; Cannon, Dell, and Dwyer, 1972b; Holman et al., 1974). To minimize possible effects of fat or other non-muscular components of myocardium on the blood flow calculation, only the slope of the curve representing the first 40 seconds of washout data was computed using a non-weighted monoexponential least squares programme, and the standard deviation of the slope was calculated. From the initial slope, an index of myocardial blood 


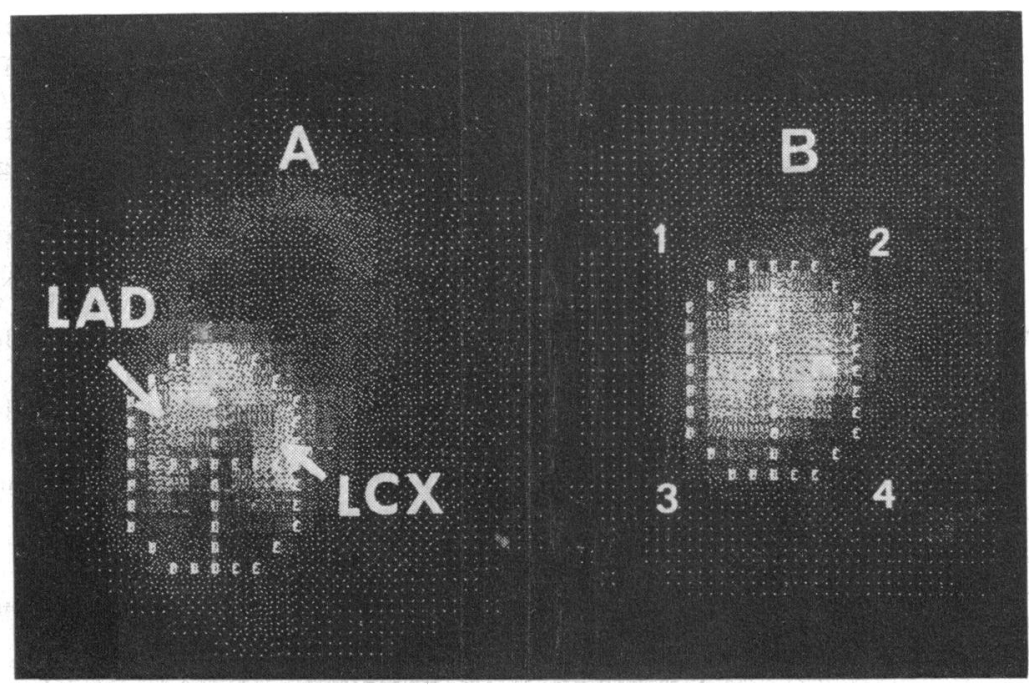

FIG. 1 Using the left anterior oblique projection, the distribution of perfusion in the left coronary artery was determined in the first 5 seconds after the xenon injection. During this phase $(A)$, xenon was primarily intravascular, thus delineating the major branches of the left anterior descending (LAD) and left circumflex (LCX) arteries. Electronic cursors were then placed over the proximal and distal portions of these vessels. (B) Once the xenon had been distributed throughout the myocardium, 4 regions were defined, representing tissue perfused by the proximal LAD (1), proximal LCX (2), distal LAD (3), and distal LCX (4). Regional clearance curves were then obtained from each quadrant.

flow in $\mathrm{ml} / \mathrm{min}$ per $100 \mathrm{~g}$ was determined, using the equation

$$
\mathrm{F} / \mathrm{W}=\frac{100 \mathrm{k} \lambda}{\mathrm{P}}
$$

where $\mathrm{k}$ was the mean slope calculated from 0 to 40 seconds, $\lambda$ was the blood/tissue partition coefficient (assumed to be 0.72 ), and $\rho$ was the specific gravity (assumed to be 1.05). During our initial investigation of the accuracy and sensitivity of this technique (Holman et al., 1974), 3 patients underwent reproducibility studies comparing the initial slopes of xenon washout; the mean difference in quadrant blood flow between the two runs was $3.0 \mathrm{ml} / \mathrm{min}$ per $100 \mathrm{~g}(3.8 \%)$ and the standard deviation was $3.2 \mathrm{ml} / \mathrm{min}$ per $100 \mathrm{~g}(4.0 \%)$. The correlation coefficient for quadrantic flows from run 1 compared with run 2 was 0.971 .

\section{Relating regional myocardial blood flow to areas of left ventricular myocardium on the ventriculogram}

Blood flow values were determined in the left anterior oblique projection (Fig. 1). Using the same spacial orientation, the left anterior oblique coronary angiogram was superimposed upon the left anterior oblique gamma camera image of the left ventricle. As a result, quadrant No. 3 represented myocardium perfused by the left anterior descending and quadrant No. 4 represented myocardium perfused by the left circumflex. Thus, the flow distal to a stenosed left anterior descending or left circumflex could be evaluated. Next, the site of asynergy (when present) was compared with the respective quadrantic myocardial blood flow values. (Analysis of asynergy corresponding to upper left anterior descending and upper left circumflex quadrants was not attempted because regions of myocardium both proximal and distal to a stenosis may overlap one another.) Evaluation of the angiograms was performed without prior knowledge of the quadrantic flow measurements, and vice versa.

\section{Results}

\section{Whole heart blood flow and asynergy}

Fifteen patients (13 men and 2 women) had coronary artery disease and no asynergy. Their mean age was 48 years (range 36 to 52). Twenty-six patients (22 men and 4 women) with coronary artery disease had asynergy. Their mean age was 48 years (range 36 to 61). Seventeen had predominant antero- 


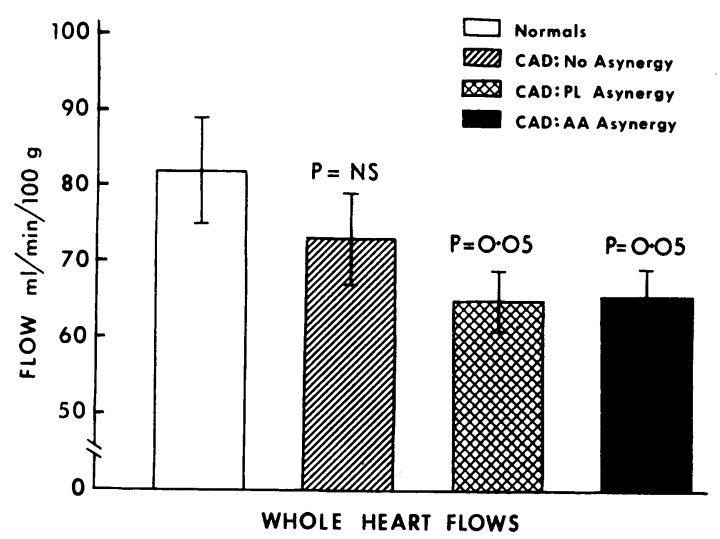

FIG. 2 Whole heart flows (mean \pm SEM) in 10 normal controls compared with 15 patients with coronary artery disease (CAD) and no asynergy, 17 patients with predominant posterolateral ( $P L)$ asynergy, and 9 patients with predominant anteroapical ( $A A)$ asynergy.

apical asynergy, and 9 had predominant posterolateral asynergy. Whole heart flow in the normal group (mean \pm standard error $=82 \cdot 1 \pm 7 \cdot 1 \mathrm{ml} / \mathrm{min}$ per $100 \mathrm{~g}$ ) was greater than any of the coronary artery disease groups. In Fig. 2, a trend in reduction of mean flow is shown from normal controls to coronary artery disease patients without asynergy $(72 \cdot 9 \pm 6 \cdot 1)^{1}$ and finally to coronary artery disease patients with anteroapical $(65.3 \pm 3.9, \mathbf{P}=0.05)$ or posterolateral asynergy (64.7 $\pm 3 \cdot 8, P=0 \cdot 05)$.

${ }^{1}$ Only significant $P$ values will be noted in remainder of text.

\section{Regional myocardial blood flow in areas of asynergy}

Posterolateral asynergy In the lower left circumflex quadrant, a trend in reduction of flow from normal controls $(91 \cdot 5 \pm 8 \cdot 8)$ to patients with coronary artery disease without posterolateral asynergy $(75.0 \pm 4.8)$, and finally to patients with coronary artery disease and posterolateral asynergy $(66.8 \pm 5 \cdot 0, \mathrm{P}<0.05)$ was also noted (Fig. 3$)$.

Anteroapical asynergy Similarly, in the lower left anterior descending quadrant, a trend in reduction of flow was again observed from normal controls $(85 \cdot 7 \pm 7 \cdot 0)$, to patients with coronary artery disease without anteroapical asynergy $(74 \cdot 9 \pm 5 \cdot 2)$ and to patients with coronary artery disease and anteroapical asynergy $(65.4 \pm 4.5, \mathrm{P}<0.05)$ (Fig. 3).

Regional myocardial blood flow in areas of akinesia compared with areas of hypokinesia

Posterolateral asynergy Of the 9 patients with posterolateral asynergy, 3 had akinesia and 6 had hypokinesia. Lower left circumflex quadrant flow in the 3 patients with akinesia was $53 \cdot 3 \pm 6 \cdot 3$, while the 6 with hypokinesia had higher mean flows $(73.5 \pm$ $5 \cdot 9, \mathrm{P}<0.05)$.

Anteroapical asynergy In the 17 patients with anteroapical asynergy, 7 had akinesia and 10 had hypokinesia. Unlike the lower left circumflex quadrant, mean lower left anterior descending quadrant flows with respect to akinesia or hypokinesia were similar.

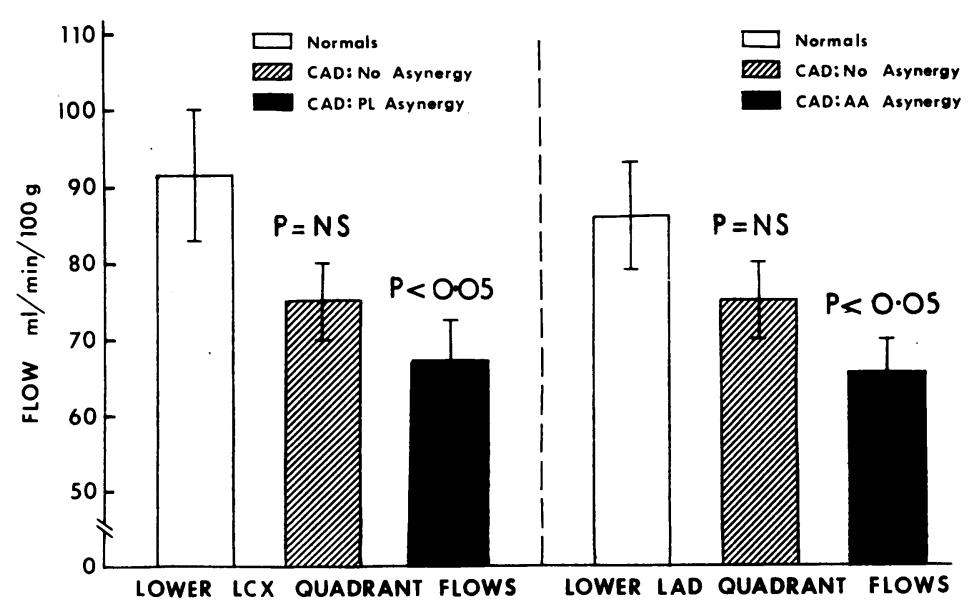

FI G. 3 The same format as in Fig. 2, only now regional myocardial blood flow (mean $\pm S E M$ ) in the lower left circumflex (LCX) and anterior descending (LAD) quadrants in normal controls are compared with patients with coronary artery disease (CAD) and no asynergy, and either posterolateral (PL) or anteroapical ( $A A)$ asynergy. 


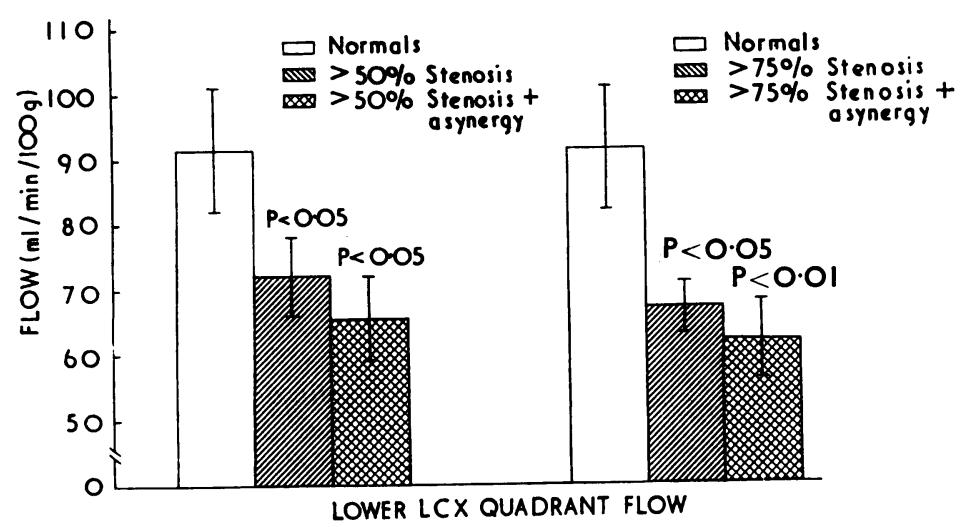

FIG. 4 Relation between regional myocardial blood flow (mean $\pm S E M$ ), degree of left circumflex $(L C X)$ stenosis, and posterolateral asynergy. $P$ values compared with 10 normal controls. 27 patients had $>50$ per cent stenosis and 7 of the 27 had asynergy. 14 patients had $>75$ per cent stenosis and 5 of the 14 had asynergy.

Relation between regional myocardial blood flow, degree of coronary artery stenosis, and presence of asynergy

(A) Degree of vessel stenosis considered separately Left circumflex Regional myocardial blood flow in the lower left circumflex quadrant distal to a left circumflex stenosis of $>50$ per cent in 27 patients is depicted in Fig. 4 (14 of these 27 patients had $>75$ per cent stenosis of left circumflex). There was a trend in reduction of mean flows from normal controls $(91.5 \pm 8.8)$ to all patients with $>50$ per cent stenosis $(71 \cdot 7 \pm 3 \cdot 8, \mathrm{P}<0.05)$ to only those patients with $>75$ per cent left circumflex stenosis $(66 \cdot 7 \pm 4 \cdot 1, P<0.01)$.

Left anterior descending Regional myocardial blood flow in the lower left anterior descending quadrant distal to a left anterior descending stenosis of
$>50$ per cent in 39 patients is depicted in Fig. 5 (19 of these 39 patients had $>75$ per cent stenosis of left anterior descending). There was again a trend in reduction of mean flows from normal controls $(85 \cdot 7 \pm 7 \cdot 0)$ to all patients with $>50$ per cent stenosis $(70.5 \pm 3.5)$ to only those patients with $>75$ per cent left anterior descending stenosis $(68 \cdot 2 \pm 4 \cdot 1, P<$ 0.05).

(B) Degree of coronary artery stenosis and asynergy Left circumflex stenosis with posterolateral asynergy Seven of the 9 patients with posterolateral asynergy had $>50$ per cent stenosis of left circumflex ( 5 had $>75 \%$ stenosis) and all patients in this group had $>75$ per cent stenosis of the right coronary artery. Since the right coronary artery was $>75$ per cent stenosed in all patients in this group, the influence of degree of left circumflex stenosis on

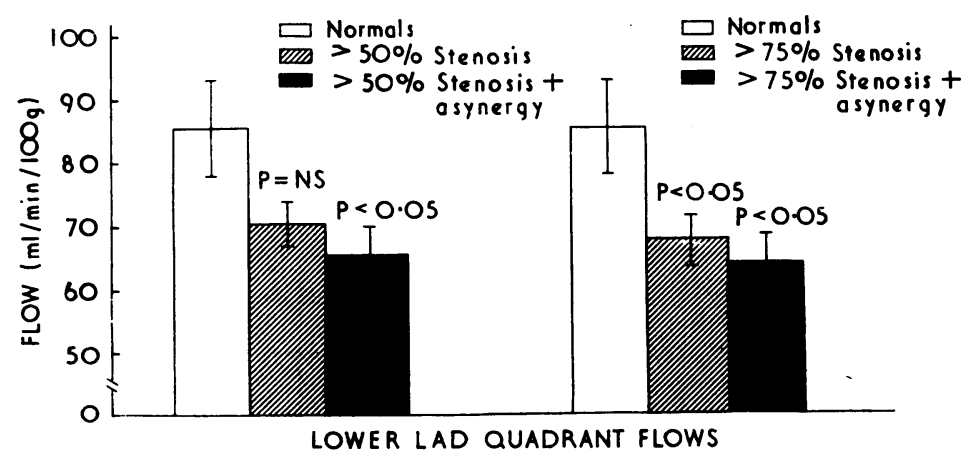

FIG. 5 Relation between regional myocardial blood flow (mean $\pm S E M)$, degree of left anterior descending (LAD) stenosis, and anteroapical asynergy. $P$ values compared with 10 normal controls. 39 patients had $>50$ per cent stenosis and 17 of the 39 had asynergy. 19 patients had $>75$ per cent stenosis and 11 of the 19 had asynergy. 
asynergy could not be reliably determined as both the right coronary artery and left circumflex may nourish the lower left circumflex quadrant in any one patient (See, Giddings, and Cosby, 1974). However, with $>50$ per cent left circumflex stenosis, the presence of posterolateral asynergy was associated with a trend toward lower left circumflex quadrant flow $(71 \cdot 7 \pm 3 \cdot 8$ to $65 \cdot 4 \pm 6 \cdot 0)$ (Fig. 4). With both $>75$ per cent left circumflex stenosis and posterolateral asynergy, this trend was again seen $(66 \cdot 7 \pm 4 \cdot 1$ to $61 \cdot 7 \pm 6 \cdot 5)$. In the remaining 2 patients with $<50$ per cent left circumflex stenosis and asynergy, the right coronary artery was stenosed $>75$ per cent and it could not be determined which vessel influenced the presence of posterolateral asynergy.

Left circumflex stenosis without posterolateral asynergy Twenty patients had $>50$ per cent left circumflex stenosis without posterolateral asynergy. Flow in these patients was greater (but not significantly) compared with patients with asynergy. In the absence of flow measurements in the right coronary artery, these values may be misleading, as we have commented earlier.

Left anterior descending stenosis with anteroapical asynergy All 17 patients with anteroapical asynergy had $>50$ per cent stenosis of the left anterior descending artery; 11 of these 17 patients had $>75$ per cent stenosis of the left anterior descending artery, with mean flow in the lower left anterior descending quadrant of $64.1 \pm 4.5, P<0.05$ (Fig. 5). With $>50$ per cent left anterior descending stenosis, the presence of anteroapical asynergy was associated with a trend in reduction of lower left anterior descending quadrant flow $(70.5 \pm 3.5$ to $65.4 \pm 4.5)$. In addition, with both $>75$ per cent left anterior descending stenosis and anteroapical asynergy, this trend was again present $(68 \cdot 2 \pm 4 \cdot 1$ to $64 \pm 4 \cdot 5)$.

Left anterior descending stenosis without anteroapical asynergy Twenty-two patients had $>50$ per cent stenosis of the left anterior descending artery and no anteroapical asynergy with lower left anterior descending quadrant mean flow greater (but not significantly) compared with patients with asynergy. Eight of the 22 patients without asynergy had $>75$ per cent left anterior descending stenosis and no anteroapical asynergy, and mean flow to the lower left anterior descending quadrant was very similar to that of patients with $>50$ per cent left anterior descending stenosis.

Relation between regional myocardial blood flow, asynergy, and collateral circulation

Left circumflex All 9 patients with posterolateral asynergy had angiographically apparent collaterals to the lower left circumflex quadrant. Thus, the influence of the absence of collaterals on flow to areas of posterolateral asynergy could not be surmised. The relative influence of collaterals on flow also could not be determined in the lower left circumflex quadrant because collaterals to the right coronary artery or left circumflex or both could be recorded as flow to this quadrant in the same patient (Cosby, Giddings, and See, 1974).

Left anterior descending In the 17 patients with anteroapical asynergy, 9 had angiographically apparent collaterals to the lower left anterior decending quadrant, while 8 did not, and mean flows were very similar. Greater than 75 per cent stenosis was present in all cases with collaterals and only 3 patients with $>75$ per cent stenosis and asynergy did not have collaterals. All 3 had greatly reduced flow ( $<45 \mathrm{ml} / \mathrm{min}$ per $100 \mathrm{~g}$ ). Eight patients had $>75$ per cent left anterior descending stenosis without anteroapical asynergy. In these 8 patients, 7 had angiographically apparent collateral flow to the lower left anterior descending quadrant with mean flows of $77 \cdot 6 \pm 7 \cdot 6$.

\section{Discussion}

Ross et al. (1964), using ${ }^{133} \mathrm{Xe}$, reported no difference in whole heart blood flow in patients with or without coronary artery disease. Though they studied 4 patients with left coronary artery disease, they did not specify the degree of stenosis. More recently, Klocke et al. (1974), in reviewing the question of whether there is a reduction of whole heart coronary blood flow per unit mass of left ventricle in patients with coronary artery disease, concluded that average myocardial blood flow was significantly decreased at rest when helium was used as a tracer. They suggested that similar correlations with ${ }^{133} \mathrm{Xe}$ clearance techniques might result (despite the methodological limitations of this technique) if regional reductions in flow could be related to localized arteriographic abnormalities. Using ${ }^{133} \mathrm{Xe}$ in that manner, Cannon et al. (1972a) noted a significant decrease in myocardial blood flow distal to a $>75$ per cent stenosed coronary artery. Dwyer, Dell, and Cannon (1973), studying regional myocardial blood flow with the same technique in patients with prior transmural infarctions, noted significantly decreased myocardial blood flow in areas of the anterior left ventricle distal to a $>80$ per cent stenosed left anterior descending coronary artery and of the right ventricle distal to a $>80$ per cent stenosed right coronary artery. (They also noted that the right coronary artery appeared to contribute very little flow to the inferior left ventricle in 
humans.) In the present series of patients, we studied regional myocardial blood flow in areas of left ventricular asynergy in 26 patients with coronary artery disease via injections of ${ }^{133} \mathrm{Xe}$ into the left coronary artery irrespective of prior clinical or electrocardiographic evidence of myocardial infarction. Ten controls with normal coronary arteries and 15 patients with coronary artery disease and no asynergy were also studied for purposes of comparison.

The effects of both extent of vessel disease and of left ventricular dysfunction (especially asynergy) on mortality have been reported by several groups (Oberman et al., 1972; Bruschke, Proudfit, and Sones, 1973a, b; Nelson, Cohn, and Gorlin, 1975; Moraski et al., 1975) and are of great prognostic importance. Our data indicate that whole heart blood flow is significantly reduced, compared with control subjects, only in coronary artery disease patients with asynergy (Fig. 2). Similarly, regional myocardial flow in the lower left anterior descending or left circumflex quadrants was also significantly reduced compared with control subjects only in patients with either anteroapical or posterolateral asynergy, respectively (Fig. 3). In patients with coronary artery disease but no asynergy, we observed whole heart and regional myocardial blood flow to be intermediate between normal controls and patients with asynergy. A trend was shown in which patients with $>75$ per cent stenosis had the greatest reduction in flow, especially when asynergy was also present (Fig. 4 and 5). Though our data do not indicate that akinesis is associated with lower flows than hypokinesis, this is not totally unexpected, since the ventriculographic finding of akinesis may not always be a precise indicator of fibrosis, i.e. non-scarred regions that are temporarily ischaemic may appear akinetic (Dyke et al., 1974). Therefore, reduced flow in some patients with coronary artery disease may be the primary cause of asynergy because of ischaemia, while in others it may be the secondary result of reduced myocardial oxygen requirements in an area of scarred left ventricle. The role of collateral vessels is also not clear from the present data, despite the finding that regional myocardial flow was very low in patients with asynergy but without collaterals.

Our study indicates that the evaluation of myocardial blood flow in patients with coronary artery disease should take into account the presence of asynergy as well as the degree of vessel stenosis and presence of collateral vessels. First, there are difficulties in evaluating the degree of stenosis of a coronary artery, which have been related to variation from observer to observer (Björk et al., 1975), as well as the finding that postmortem evaluation of stenosis and angiographic evaluation may be at variance (Vlodaver et al., 1973). Second, vessels may at one time have been more severely stenosed with subsequent recanalization (Chandler, 1972). These two observations may explain the similar flow data in patients with $>50$ per cent stenosis compared with $>75$ per cent stenosis. On the other hand, asynergy alone may be an unreliable indicator of reduced flow since asynergic regions may consist of islands of viable tissue interspersed within a sea of fibrosis or vice versa (Schwartz and Mitchell, 1962). In addition, collateral circulation may possibly alter flows in areas of asynergy (Banka, Bodenheimer, and Helfant, 1974), and asynergy in the absence of coronary artery disease (as in primary myocardial disease) may be associated with normal or high coronary blood flow (Horwitz et al., 1974). Thus, while the present study confirms the advantages of measuring regional myocardial blood flow, rather than only whole heart blood flow, it also suggests the need to relate flow data to the results of two-state left ventriculography (Cohn and Gorlin, 1975) to determine total and regional contractile reserve. There is also a need for further regional myocardial blood flow measurements in a second state in which either the heart is metabolically stressed or maximal hyperaemia is induced (Gould et al., 1974). These additional data will help to clarify the role of collateral vessels as well as assessing the haemodynamic significance of coronary artery lesions on the arteriogram.

\section{References}

Banka, V. S., Bodenheimer, M. M., and Helfant, R. H. (1974) Determinants of reversible asynergy: effect of pathologic $Q$ waves, coronary collaterals, and anatomic location. Circulation, 50, 714.

Björk, L., Spindola-Franco, H., Van Houten, F. X., Cohn, P. F., and Adams, D. F. (1975). Comparison of observer performance with $16 \mathrm{~mm}$ cinefluorography and $70 \mathrm{~mm}$ camera fluorography in coronary arteriography. American fournal of Cardiology, 36, 474.

Bruschke, A. V. G., Proudfit, W. L., and Sones, F. M., Jr (1973a). Progress study of 590 consecutive nonsurgical cases of coronary disease followed 5 to 9 years. I. Arteriographic correlations. Circulation, 47, 1147.

Bruschke, A. V. G., Proudfit, W. L., and Sones, F. M., Jr. (1973b). Progress study of 590 consecutive nonsurgical cases of coronary disease followed 5 to 9 years. II. Ventriculographic and other correlations. Circulation, 47, 1154.

Cannon, P. J., Dell, R. B., and Dwyer, E. M., Jr. (1972a). Regional myocardial perfusion rates in patients with coronary artery disease. fournal of Clinical Investigation, 51, 978.

Cannon, P. J., Dell, R. B., and Dwyer, E. M., Jr. (1972b) Measurement of regional myocardial perfusion in man with ${ }^{133}$ Xenon and a scintillation camera. Fournal of Clinical Investigation, 51, 964.

Chandler, A. B. (1972). Thrombosis in the development of coronary atherosclerosis. In Atherosclerosis and Coronary 
Heart Disease, pp. 28-34. Ed. by W. Likoff, B. L. Segal, and W. Insull, Jr. Grune and Stratton, New York.

Cohn, P. F., and Gorlin, R. (1975). Dynamic ventriculography and the role of the ejection fraction. American fournal of Cardiology, 36, 529.

Cohn, P. F., Gorlin, R., Adams, D. F., Chahine, R. A., Vokonas, P. S., and Herman, M. V. (1974a). Comparison of biplane and single plane left ventriculograms in patients with coronary artery disease. American fournal of Cardio$\log y, 33,1$.

Cohn, P. F., Levine, J. A., Bergeron, G. A., and Gorlin, R. (1974b). Reproducibility of the angiographic left ventricular ejection fraction in patients with coronary artery disease. American Heart Fournal, 88, 713.

Cosby, R. S., Giddings, J. A., and See, J. R. (1974). Coronary collateral circulation. Chest, 66, 27.

Dwyer, E. M., Jr., Dell, R. B., and Cannon, P. J. (1973). Regional myocardial blood flow in patients with residual anterior and inferior transmural infarction. Circulation, 48, 924.

Dyke, S. H., Cohn, P. F., Gorlin, R., and Sonnenblick, E. H. (1974). Detection of residual myocardial function in coronary artery disease using postextrasystolic potentiation. Circulation, 50, 694.

Gould, K. L., Hamilton, G. W., Lipscomb, K., Ritchie, J. L., and Kennedy, J. W. (1974). Method for assessing stressinduced regional malperfusion during coronary arteriography. American fournal of Cardiology, 34, 557.

Holman, B. L., Adams, D. F., Jewitt, D., Eldh, P., Idoine, J., Cohn, P. F., Gorlin, R., and Adelstein, S. J. (1974). Measuring regional myocardial blood flow with ${ }^{133} \mathrm{Xe}$ and the Anger camera. Radiology, 112, 99.

Horwitz, L. D., Curry, G. C., Parkey, R. W., and Bonte, F. J. (1974). Effect of isoproterenol on coronary blood flow in primary myocardial disease. Circulation, 50, 560.

Klocke, F. J., Bunnell, I. L., Greene, D. G., Wittenberg, S. M., and Visco, J. P. (1974). Average coronary blood flow per unit weight of left ventricle in patients with and without coronary artery disease. Circulation, 50, 547.

Moraski, R. E., Russell, R. O., Jr., Smith, M., and Rackley, C. E. (1975). Left ventricular function in patients with and without myocardial infarction and one, two or three vessel coronary artery disease. American fournal of Cardiology, 35, 1.

Nelson, G. R., Cohn, P. F., and Gorlin, R. (1975). Prognosis in medically-treated coronary artery disease: influence of ejection fraction compared to other parameters. Circulation, 52, 408.

Oberman, A., Jones, W. B., Riley, C. P., Reeves, T. J., Sheffield, L. T., and Turner, M. E. (1972). Natural history of coronary artery disease. Bulletin of the New York Academy of Medicine, 48, 1109.

Ross, R. S., Ueda, K., Lichtlen, P. R., and Rees, J. R. (1964). Measurement of myocardial blood flow in animals and man by selective injection of radioactive inert gas into the coronary arteries. Circulation Research, 15, 28.

Schwartz, C. J., and Mitchell, J. R. A. (1962). The relation between myocardial lesions and coronary artery disease. I. An unselected necropsy study. British Heart fournal, 24, 761 .

See, J. R., Giddings, J. A., and Cosby, R. S. (1974). Regional left ventricular performance in infarction and angina (abstract). Clinical Research, 22, 153A.

Vlodaver, Z., Frech, R., Van Tassel, R. A., and Edwards, J. E. (1973). Correlation of the antemortem coronary arteriogram and postmortem specimen. Circulation, 47, 162.

Requests for reprints to Dr. Peter F. Cohn, Cardiovascular Division, Department of Medicine, Peter Bent Brigham Hospital, 721 Huntington Avenue, Boston, Massachusetts 02115, U.S.A. 